\title{
A Guide to Finite Element Simulations of Thermal Barrier Coatings
}

\author{
Martin Bäker ${ }^{1} \cdot$ Philipp Seiler $^{2}$
}

Submitted: 22 December 2016/in revised form: 12 June 2017/Published online: 6 July 2017

(C) ASM International 2017

\begin{abstract}
To understand the stress evolution and failure mechanisms of thermal barrier coatings (TBCs), finite element simulations are an invaluable tool. Simulations are especially useful to unwrap complex interactions of different phenomena at high temperature, including creep, sintering, diffusion, and oxidation. However, the correct setup and evaluation of a finite element model for this problem are difficult. This article reviews critical issues in modelling TBC systems. Some of the most important aspects are as follows: (a) stresses in 3D simulations may differ considerably from 2D models; (b) the interface shape strongly affects the stresses and using an idealized geometry may underestimate stresses; (c) crack propagation requires simulating sufficiently large regions to correctly capture stress redistribution; (d) a correct description of the material behaviour (visco-plasticity, TGO growth, sintering) is crucial in determining the stress state. The article discusses these and other issues in detail and provides guidelines on the choice of model parameters, boundary conditions, etc. The paper also points out open questions in modelling TBC systems and discusses aspects of verification and validation.
\end{abstract}

Keywords finite element modelling · plasma spray forming · thermal barrier coatings (TBC) - thin film coatings

Martin Bäker

martin.baeker@tu-bs.de

1 Institut für Werkstoffe, TU Braunschweig, Langer Kamp 8, 38106 Braunschweig, Germany

2 Department of Engineering, University of Cambridge, Cambridge CB2 1PZ, UK

\section{Introduction}

Thermal barrier coatings (TBCs) are used in aircraft engines and stationary gas turbines to protect materials in the combustion chamber from the extreme gas temperatures. Turbine blades, for example, are usually made from nickel-based superalloys with a melting temperature below the temperature of the process gas. These blades are therefore cooled from the inside and protected on top with a ceramic coating that has a low thermal conductivity and thus creates a considerable temperature gradient of $100 \mathrm{~K}$ or more (Ref 1). Between the ceramic coating and the nickel-base substrate, an intermediate layer (bond coat, BC) is applied that serves as corrosion and oxidation protection and improves the adhesion of the ceramic. Thermal barrier coatings can be applied by physical vapour deposition (EB-PVD) or by atmospheric plasma-spraying (APS). EB-PVD coatings usually possess a longer lifetime due to their greater strain tolerance, but are more expensive as well (Ref 1). The structure and a micrograph of a plasma-sprayed TBC system are shown in Fig. 1.

Despite the success of thermal barrier coatings, exploiting their full potential is hampered by their limited lifetime. During service, oxygen diffuses through the ceramic thermal barrier coating and reacts with the aluminium in the bond coat to form an oxide layer (thermally grown oxide, TGO). Coatings frequently spall off when the TGO exceeds a critical thickness of the order of 1$10 \mu \mathrm{m}(\operatorname{Ref} 1,2)$ due to the large stresses developing within the TGO during growth and during cooling, see "Causes of Stress" section. Predicting the lifetime of thermal barrier coating systems is therefore an important goal.

To achieve this goal, it is important to understand the stress evolution within TBC systems. This can be done 


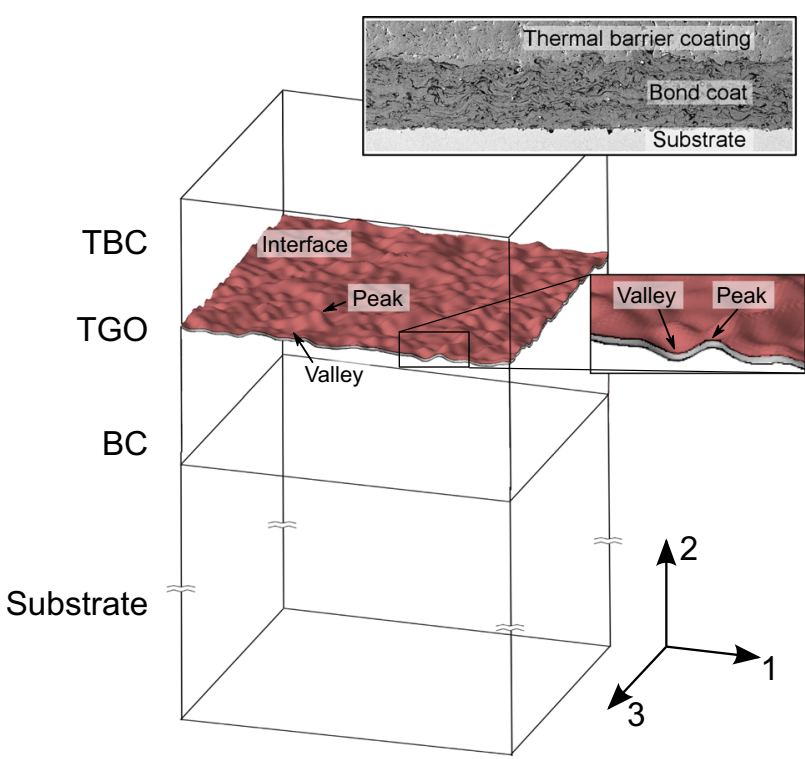

Fig. 1 Schematic structure of a thermal barrier coating system. The substrate is coated with a bond coat (BC) and the thermal barrier coating (TBC); during service, a thermally grown oxide layer (TGO) forms. Stresses at the interface are crucial in determining the lifetime of the TBC system. Stress maxima frequently occur at the "peak" and "valley" position of the interface. The inlay at the upper right shows an SEM image of a TBC system directly after coating

with finite element simulations, which allow to simulate how thermal cycling and TGO growth affect the stress state in a thermal barrier coating (Ref 3, 4, 5, 6, 7).

Finite element simulations of TBC interface stresses have been performed now for approximately 30 years (Ref $5)$. Due to these simulations, it is quite well-established how stresses evolve in a coating system (Ref 6): if a system is heated up from a stress-free state, the difference in the thermal expansion coefficient (CTE) causes stresses at the interface. Because the interface is rough, stresses perpendicular to the interface can develop. Stresses are usually largest at the regions where the bond coat height in the roughness profile has a maximum ("peaks") or a minimum ("valleys"); see Fig. 1. If no or a thin TGO is present, these stresses are tensile in the peak region and compressive in the valley region of the interface. During cycling of a gas turbine, TGO growth causes growth and thermal mismatch stresses that shift the stress state to become tensile in the "valley" region of the roughness profile and compressive in the peak region. Stress relaxation (due to plastic or visco-plastic deformation) changes the stress state, especially at high temperatures.

However, the evolution of the stress state is influenced by a large number of additional effects like sintering, crack propagation, the detailed kinetics of TGO growth, and the microstructure and anisotropy of the coating, as will be discussed below. The development of new coating materials or coating strategies [like double-layered (Ref 8 ) or graded coatings (Ref 9)] also requires simulations to understand their stress evolution and failure behaviour. Therefore, finite element models of TBC systems are still of great interest even after more than 30 years of model development.

Due to the complex interplay between growth and thermal stresses in a TBC system and the effects discussed in the last paragraph, there is a large number of modelling decisions to be made in setting up a finite element model, for example, dimensionality of the model, geometry of the interface between bond coat and TBC, choice of material parameters, inclusion of effects like sintering, implementation of crack propagation, choice of thermal cycle. The aim of this paper is to infer guidelines from existing studies for setting up such simulations and for deciding which of these effects to include. Key references are included where appropriate, but a full literature review is beyond the scope of the paper. The focus of this paper is the simulation of the stress development in a thermal barrier coating in microscale models where the stresses at the interface are the main quantity of interest. The paper mainly deals with the simulation of APS coatings, although many of the topics covered also apply to the simulation of EB-PVD coatings.

The paper is organized as follows: in "Causes of Stress" section, an overview of causes of stress in TBC systems is given. "Model Setup" section discusses different aspects of setting up the finite element model like dimensionality, interface shape or crack propagation. In "Influence of System Parameters" section, the influence of different system parameters (material parameters, thermal cycle, implementation of oxide growth) is discussed. The final "Open Questions" section discusses aspects of the TBC failure behaviour that are currently not reproduced correctly by most finite element models (for example, slow growth of microdelaminations) or that are usually not included in the model setup (for example, the microstructure of the coating and the resulting material anisotropy). Finally, the problem of validating and verifying simulation models is discussed.

\section{Causes of Stress}

There are two main causes of stress in a TBC system: thermal mismatch stresses are due to the differences in the CTE between the materials. Usually, the CTE of the substrate and the bond coat is similar, but larger than that of the TBC material which is in turn larger than that of the TGO. Since the substrate is considerably thicker than the coating, its thermal expansion governs the thermal strains in the in-plane direction (the 1-3-plane from Fig. 1).

Diffusion of oxygen through the TBC causes the growth of the TGO layer. Although the growth is anisotropic and 
occurs mainly in the direction perpendicular to the interface (the 2-direction in Fig. 1), there is also some lateral growth once the TGO has formed. The TGO growth becomes slower over time due to the parabolic growth of $\alpha$ alumina which leads to a relatively high growth rate at small thickness (Ref 10). This TGO growth has two effects on the stress state: on the one hand, the volume increase causes large compressive stresses in the TGO, especially in the in-plane direction. On the other hand, the small CTE of the TGO changes the thermal stresses during a temperature change.

To understand the effects of these two causes of stress (CTE mismatch and TGO growth), it is helpful to distinguish stresses perpendicular to the interface from in-plane stresses. In APS coatings, a rough interface (see Fig. 1) is needed to ensure adhesion of the coating by mechanical interlocking. As long as no or only a thin TGO is present, stresses perpendicular to the interface are governed by the CTE mismatch between the metallic BC and the ceramic TBC. If stresses relax during hot time, the stress after cooling is tensile at the peak and compressive at the valley region of the interface.

TGO growth causes growth strains in the in-plane direction because the TGO is constrained by the surrounding material. Since the interface is rough, these strains shift the stress to be compressive in the TBC peak and tensile in the TBC valley region. Upon cooling, the smaller CTE of the TGO exacerbates this stress shift: the TGO contracts less than the TBC, causing additional compressive stresses in the peak and tensile stresses in the valley region. These two effects lead to the well-known stress shift from tension to compression in the peak and from compression to tension in the valley of the TBC (see also Fig. 4) (Ref 6). These stresses are important because they may initiate delamination cracks at the interface. (Note that delamination cracks may also propagate in mode II (Ref 11).

In evaluating these stresses in a simulation, it is important to check whether the maximum stress actually occurs at the interface or at a point situated further away from the interface (Ref 12). Cracks may form at a distance to the TBC/TGO interface, as observed experimentally in some cases (Ref 1$)$.

In-plane stresses develop even with a perfectly plane interface. The high coefficient of thermal expansion of the substrate $\left(\sim 16 \times 10^{-6} \mathrm{~K}^{-1}\right)$ and the large substrate volume leads to tensile in-plane stresses in the TBC upon heating that may cause segmentation cracks in the TBC. Although such cracks may be beneficial because they increase the strain tolerance of the TBC (Ref 13), they may become problematic if they penetrate into the TGO and the bond coat (Ref 14). Segmentation cracks can also interact with cracks forming at the interface (Ref 15). After stresses relax at hot time, in-plane stresses become compressive during cooling. If delamination cracks form at the interface, compressive stresses in the coating may cause buckling of the coating when a critical crack length is reached. Furthermore, the in-plane stresses also affect the perpendicular stresses: compressive stresses in the TGO may be reduced by increasing the amplitude of the interface ("wrinkling"). The shift of tensile stresses from peak to valleys occurs at smaller TGO thickness if this effect is present (Ref 16). The lateral growth of the TGO is a second cause for this effect (Ref 17) because it can lead to large compressive stresses in the TGO (Ref 18). This change in the interface geometry increases the growth and thermal mismatch stresses in the 2-direction.

Although this section-as well as studies of TBC failure in general-focuses on the stress state, it is important to keep in mind that the failure of a TBC system is a straincontrolled problem, determined by thermal mismatch and growth strains. In interpreting the stress evolution during cooling, it is thus important to notice that Young's modulus of all materials is temperature dependent so that stresses at the end of hot time will increase upon cooling simply due to the increase in Young's modulus.

\section{Model Setup}

\section{Model Dimensionality}

Finite element simulations of TBC systems require a large number of elements because the scale of the interface region is usually much smaller than the thickness of the specimen so that strong mesh refinement is needed. (This is sometimes remedied by ignoring the substrate, but doing so may be problematic as explained in "Influence of Substrate" section.) To reduce computational cost, two-dimensional models are frequently used, although there are some simulations performed in 3D (Ref 19, 20, 21).

A simple finite element model allows to study the quantitative influence of the model dimension, see Fig. 2. The TBC thickness was $200 \mu \mathrm{m}$. The TGO thickness was varied and was constant at every point normal to the interface. The FE mesh was refined near the TGO with the smallest element size of $\sim 0.25 \mu \mathrm{m}$. To model a infinite coated surface, nodes on the lateral faces of the model were allowed to move in the 2-direction, but the movement in 1and 3-direction was restricted by tying rigid planes to nodes at the faces which were allowed to move in 1- or 3direction as explained in more detail in "Mechanical Boundary Conditions" section. Two different interface geometries were compared: a simple, grooved interface resembling the 1-dimensional sinusoidal interface of a 2Dmodel and a more complex 2-dimensional sinusoidal, 


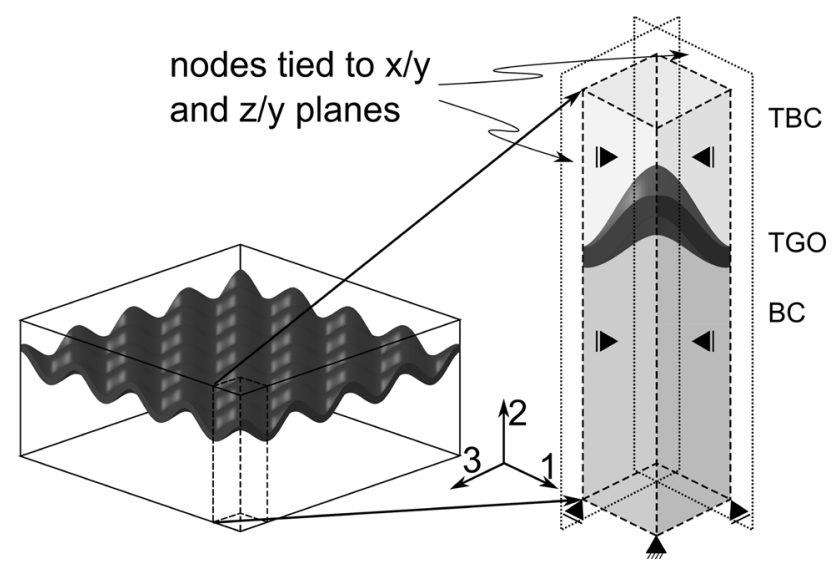

Fig. 2 3-Dimensional model geometry

calculated as the product of two sine-functions. Because the simulation was compared to a simplified model system that was described in Ref 22, no substrate was included in the simulations. Material data used were identical to those in Ref 17.

Elastic cooling stresses from a stress-free high-temperature state at $1000^{\circ} \mathrm{C}$ are calculated. The influence of the TGO on the cooling stresses can be covered by varying the TGO thickness at elevated temperature. The interfacial wavelength $L$ and amplitude $A$ are constant for all simulations ( $L=30 \mu \mathrm{m}, A=5 \mu \mathrm{m})$.

Figure 3 shows the $\sigma_{22}$-stress distribution at the TGO/ TBC interface for different TGO thicknesses $s \in\{0,2,5 \mu \mathrm{m}\}$. Both interfaces show the shift from tension to compression in peak regions and compression to tension in the valley regions with increased TGO thickness that was explained in "Causes of Stress" section. One difference between the two models is that the maximum tensile stress for the largest TGO thickness occurs at the valley position for the grooved profile, but lies at the slope for the sinusoidal profile.

Figure 4 shows a quantitative analysis of the $\sigma_{22}$-stresses in the valley and peak regions of both interfaces as well as $\sigma_{22}$-stresses at the saddle point of the 2-dimensional sinusoidal interface. The stress shift at the peak was found at slightly smaller thickness value for the 2-dimensional sinusoidal interfaces. This effect is negligible in the valley region.

The stresses in the valley region are almost identical for all thickness values. Compressive stresses in the peak region are about half as large at the grooved interface ( $\sim 100 \mathrm{MPa}$ smaller for $s>2 \mu \mathrm{m})$. Higher stresses in the 2-dimensional sinusoidal interface can be explained by the smaller BC volume surrounded by the TBC in the peak. Therefore, the stresses in the $\mathrm{BC}$ and in the $\mathrm{TBC}$ are strongly influenced by the TGO. Furthermore, the increased TGO influence at the peak explains the stress at lower $s$. This effect has no influence on the stresses in the valley.

The stress evolution at the saddle point corresponds to the behaviour in the valley with a lower overall stress level for $s<1 \mu \mathrm{m}$. However, the stress shift near the saddle point occurs at lower $s$ compared to the valley regions. In all simulations, the maximal stresses were found at the interfaces. The location of the maximal tensile stresses for large $s$ lies in an off-valley position in the 2-dimensional sinusoidal interface as shown in Fig. 3. Maximal compressive stresses are located in the peak after the stress shift in both models.

In summary, comparing elastic cooling stresses over TGO thickness of a groove profile with a 2-dimensional sinusoidal interface shows that a 2D-model can be used for a qualitative analysis of the stress evolution near the interface. In both cases, stresses shift from tension to compression in the valley region and from compression to tension in the peak region, respectively. High tensile stresses were found in the valley with increasing TGO thickness. Compressive stresses in the peak region are underestimated in the grooved model, showing that a 2Dsimulation does not correctly predict stresses for more complex interface shapes.

In a two-dimensional simulation, either generalized plane strain or axisymmetric elements have to be used (see also "Mechanical Boundary Conditions" section). Although the specimen radius is usually large compared to the interface size in an axisymmetric sample, the stress state is nevertheless affected by this choice. To see this, consider the case of a straight interface. In a generalized plane strain simulation, the strains in the three spatial directions due to a difference in the thermal expansion are decoupled and there are no stresses in the 2-direction. If axisymmetry is assumed, thermal expansion in the 2-direction causes stresses in the 3-direction. If cracks propagate at the interface between bond coat and TBC (without a TGO being present), the difference in the CTE causes additional stresses in the 2-direction in front of the crack tip in an axisymmetric model.

The decision whether to model in two or three dimensions is closely linked to the interface geometry (see the next section). If crack propagation is simulated (see "Crack Propagation" section), a crack in a 3D model can show different behaviour than in 2D because it can circumvent regions of compressive stresses.

\section{Interface Geometry}

Frequently, a sinusoidal interface or an interface consisting of two semicircles (Ref 23) is assumed, modelling a system with a simple periodic interface geometry. Figure 5 shows the cooling stresses in a simple TBC system with no TGO 

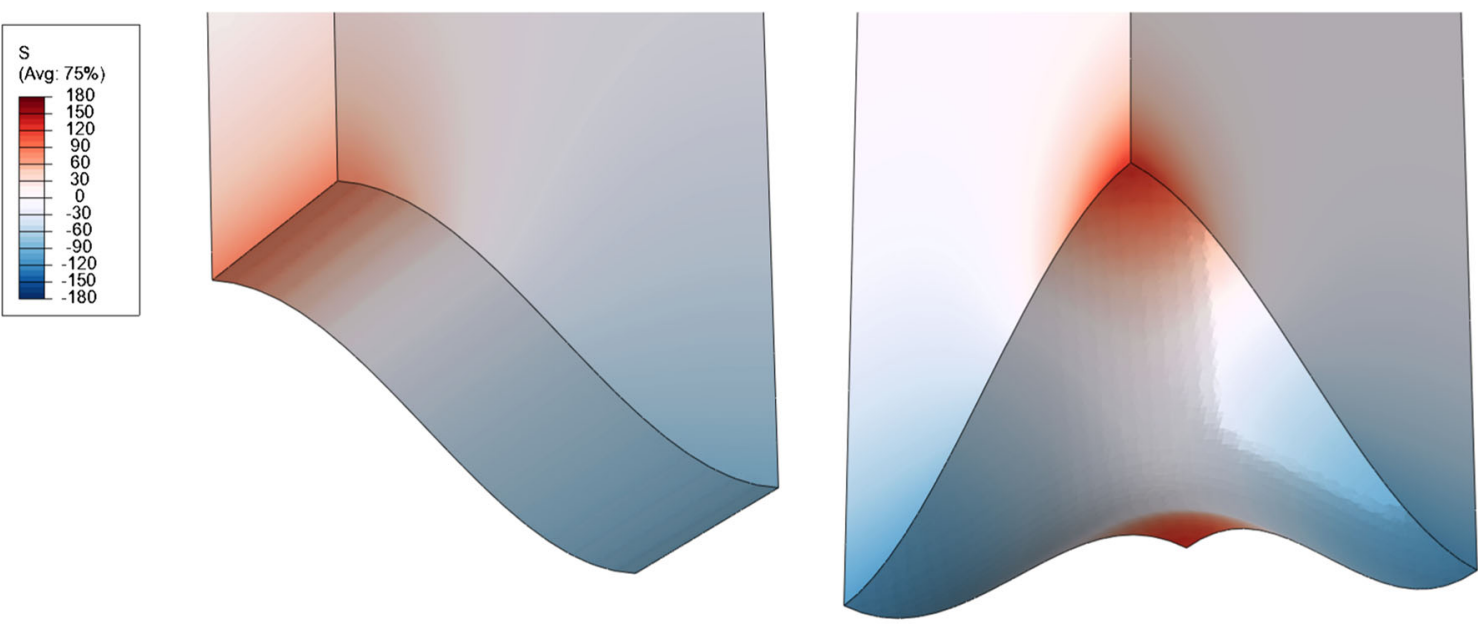

(a)
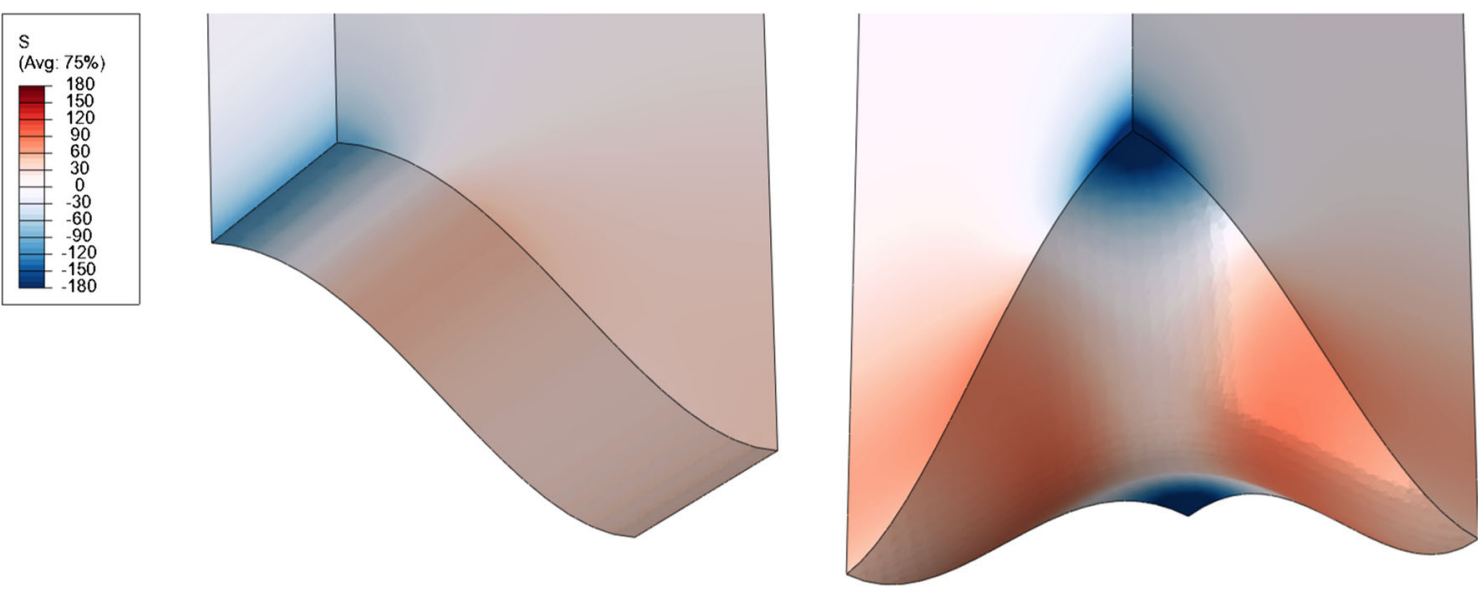

(b)
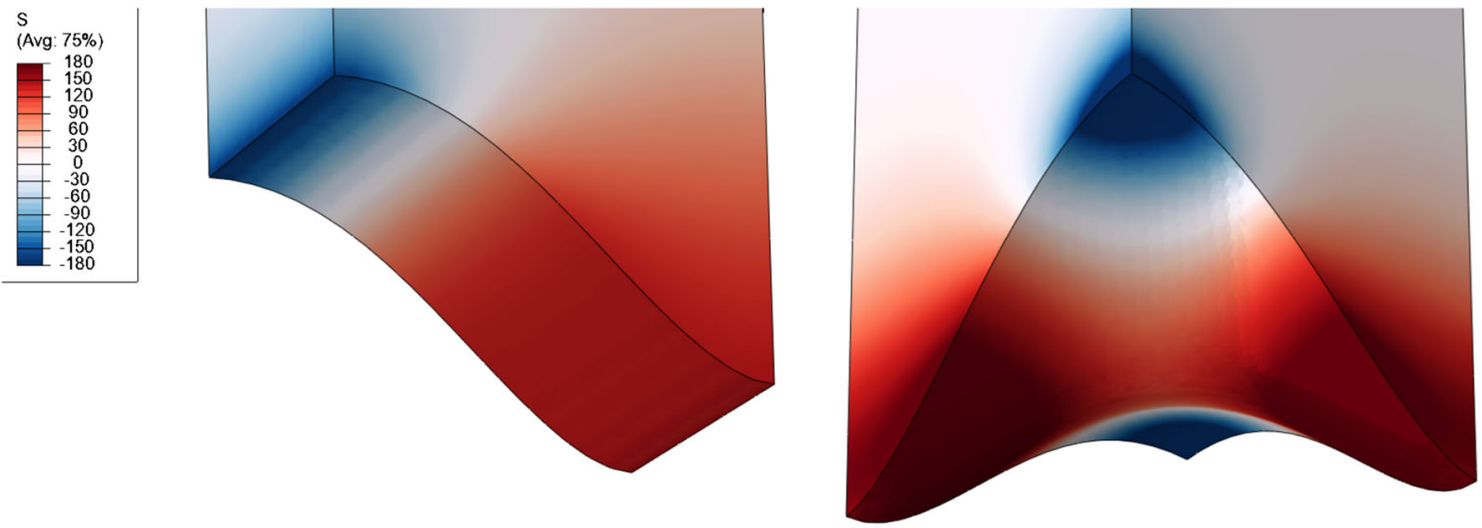

(c)

Fig. $3 \sigma_{22}$-stresses in MPa after cooling at the TBC/TGO interface of the grooved model (left) and the model with the 2-dimensional sinusoidal interface (right) for different TGO thicknesses $s$. (a) $s=0 \mu \mathrm{m}$. (b) $s=2 \mu \mathrm{m}$. (c) $s=5 \mu \mathrm{m}$

present for three different shapes of the interface. Qualitatively, the stress states are similar, although the interface with two semicircles shows an additional maximum of the 22 -stress at the vertical part of the interface. The sawtoothed-shaped interface shows a pronounced stress maximum at the corners; theoretically, a stress singularity is to be expected here due to the symmetric boundary conditions employed. Similar results were also shown in Ref 24.

A more realistic interface shape can be based on micrographs of cross sections of the interface obtained 
using optical microscopy or SEM. The resulting structure is two-dimensional and can be meshed using tools like OOF (Ref 25). Examples for such simulations are Ref 25, 26, 27, 28.

Although such simulations can yield valuable insights into the effect of the microstructure on stresses or crack propagation, quantitatively the resulting stresses differ from the stresses in the full three-dimensional system as shown in the previous section. This effect is especially pronounced if voids are present. To see this, compare the geometry factor $Y=2 / \pi$ of a lens-shaped crack (representing a three-dimensional void) with that of a plane elliptic crack $(Y=1)(\operatorname{Ref} 29)$. Stresses at voids will thus be overestimated in a two-dimensional simulation. The

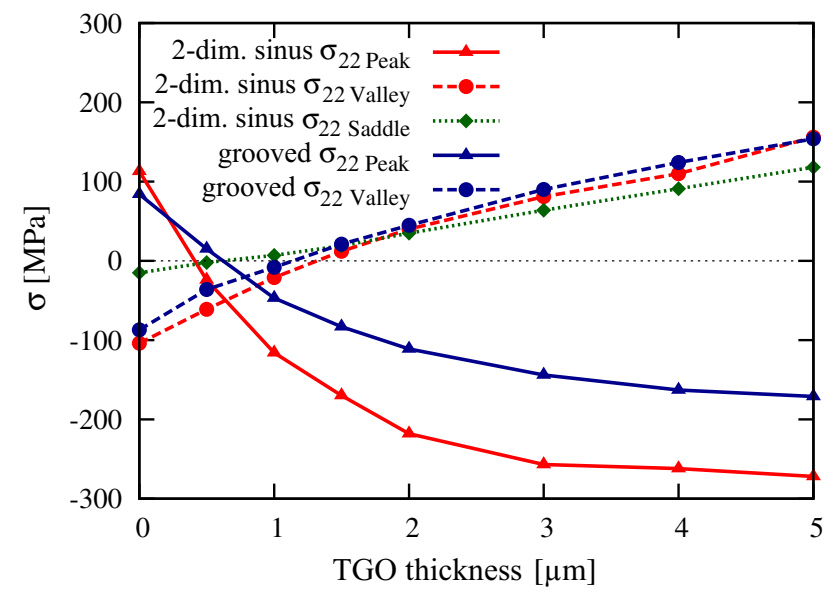

Fig. $4 \sigma_{22}$-Stresses at the peak, the valley, and at the saddle point of grooved and 2-dimensional sinusoidal interfaces over TGO thickness. Stresses were evaluated at the integration points closest to the desired peak or valley regions at the TGO/TBC interface inside the TBC same problem may occur in a two-dimensional crack propagation analysis.

To model a realistic interface shape in three dimensions, the height profile of the interface can be determined before applying the top coat using white light interferometry as done in Ref 19. Alternatively, a simulation model of the coating process can be used to calculate the shape of the interface (Ref 30). A TGO of uniform thickness can then be applied for a cooling simulation; alternatively, a growth algorithm as discussed in "Implementation of Oxide Growth" section can be used to create the TGO. The discussion in this and the previous section shows that for a quantitatively correct stress analysis, a three-dimensional simulation with a realistic interface geometry is required. However, in many cases material properties are not known very precisely (see "Material Models" section) so that stress results cannot be expected to be precise. If this is the case and if the interest is more in understanding the main features of stress evolution than in performing quantitatively accurate calculations, a 2D simulation (with an idealized interface geometry) is advantageous due to its greater simplicity.

\section{Mechanical Boundary Conditions}

A micromechanical model can be considered as a representative volume element which is periodic in the in-plane direction. Since periodic boundary conditions are often difficult to implement in finite element software, symmetry boundary conditions can be used. For this to be correct, the interface has to be perpendicular to the boundary; otherwise, spurious stress maxima will occur due to the notch at the corner (see also Fig. 5). The boundary conditions must
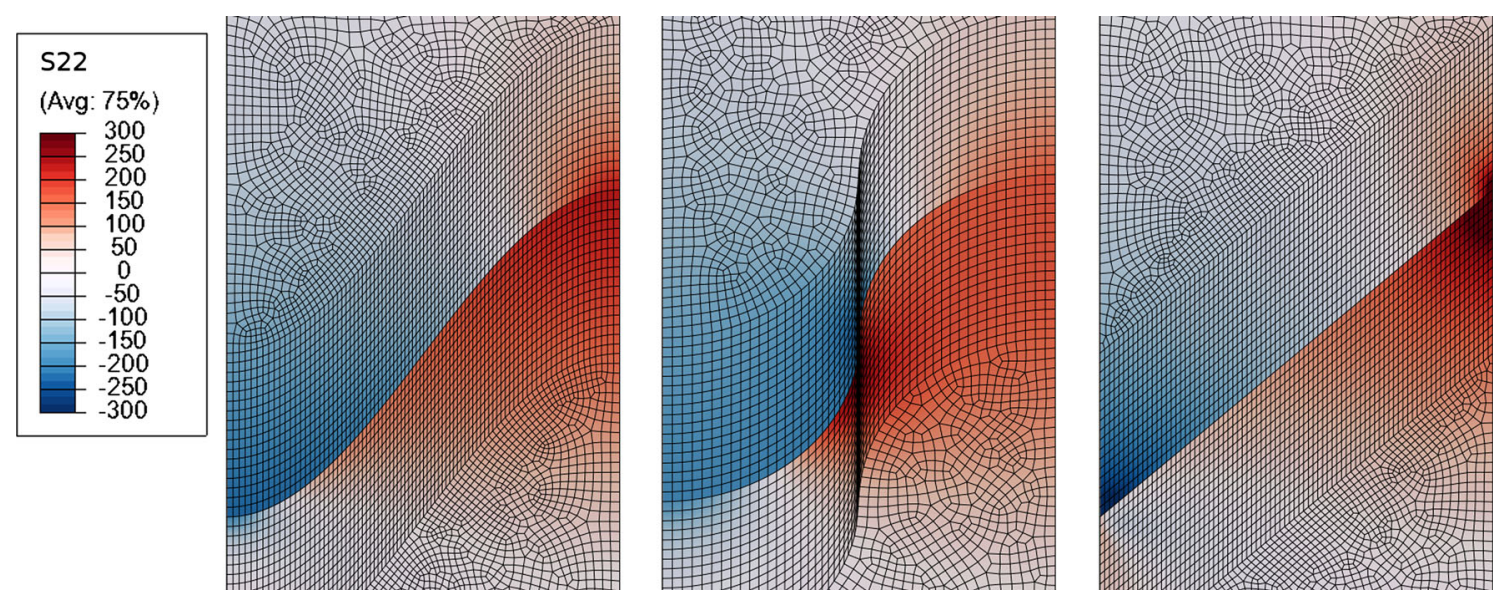

Fig. 5 Dependence of the 22-stress state on the shape of the interface. The standard sine-shaped interface has a smooth stress distribution. In the semicircular shape, there are additional radial stresses at the vertical part of the interface due to the CTE mismatch. The sawtoothed-shaped interface has a stress maximum (theoretically, a stress singularity) at the edges. The 2D axisymmetric model uses no TGO and is cooled from a stress-free state with purely elastic materials. Bond coat thickness $130 \mu \mathrm{m}$, TBC thickness $250 \mu \mathrm{m}$, substrate thickness $12.7 \mathrm{~mm}$ 
also be chosen to allow for thermal expansion while keeping the rectangular or cuboidal shape of the simulation volume. One way to achieve this is to define an auxiliary contact surface on one side of the simulation volume. Nodes on the boundary are tied to this surface in the normal direction as already explained in the context of Fig. 2 (Ref 31). Another possibility is to use constraint equations that restrict all nodes on this boundary to displace by the same amount (Ref 28).

In a $3 \mathrm{D}$ simulation, the described boundary condition has to be defined in both in-plane directions (see boundary conditions in Fig. 2). If the simulation is $2 \mathrm{D}$, either axisymmetric or generalized plane strain elements have to be used to determine the strains in the third direction. Simple plane strain leads to large compressive stresses in the 33-direction upon heating as the following simple estimate shows: assume a ceramic top coat on a very thick nickel substrate in a stress-free state at room temperature. If plane strain conditions are assumed, the thermal strain in the 3-direction is given by $\alpha_{\mathrm{TBC}} \Delta T$, where $\alpha_{\mathrm{TBC}}$ is the thermal expansion coefficient (CTE) of the TBC and $\Delta T$ is the temperature difference. If generalized plane strain conditions are assumed instead, the substrate expands with its CTE of $\alpha_{\text {substrate }}$ so that the strain in the TBC is reduced to $\left(\alpha_{\mathrm{TBC}}-\alpha_{\text {substrate }}\right) \Delta T$. For example, if the temperature difference is $1000^{\circ} \mathrm{C}$, Young's modulus of the TBC is $48 \mathrm{GPa}$ and the CTEs are $\alpha_{\text {substrate }} \approx 1.6 \times 10^{-5} \mathrm{~K}^{-1}$ and $\alpha_{\mathrm{TBC}} \approx 1.2 \times 10^{-5} \mathrm{~K}^{-1}$ at the final temperature, the 33stress in the TBC can be estimated to $576 \mathrm{MPa}$ for plane strain conditions and $192 \mathrm{MPa}$ for generalized plane strain conditions. If stresses relax at high temperatures, large tensile stresses build up during cooling.

It might be argued that stresses in the 33-direction are irrelevant, since only stresses in 11- and 22-direction are usually evaluated in a 2D simulation. However, since the materials show plastic or visco-plastic behaviour at high temperatures that is governed by the von-Mises-stress, stresses in 33-direction strongly affect plastic flow. In addition, Poisson's ratio also causes an influence of the 33-strains on the stresses in the other directions.

\section{Crack Propagation}

Failure in TBC systems usually occurs by delaminations at or near the interface between bond coat, TGO and TBC. These delaminations are caused by the growing of microcracks.

It is not straightforward to estimate the behaviour of cracks from a micromechanical stress simulation because the formation and propagation of microcracks changes the stress state significantly. For example, the Freborg model of TBC failure (Ref 6) assumes that cracks start at the peak position of the roughness profile when the TGO is thin and the stress state is tensile in this region and that the cracks propagate as the tensile region shifts due to TGO growth (see "Causes of Stress" section). However, if a crack forms near the peak position, tensile stresses cannot be transferred anymore so that the stress state is altered by the presence of the crack. Figure 6 shows a simple two-dimensional simulation of a TBC system without a TGO. The system is cooled from a stress-free state. To simulate crack propagation, elements along a thin row at the interface are deleted step by step after cooling, so there is no crack propagation criterion used in this simulation. Its aim is simply to show how the stress field shifts when a crack propagates and thus to illustrate the need for a crack propagation analysis. As can be seen, the tensile stress field moves with the crack tip because the compressive stresses near the valley region need to be compensated. Although the stresses in the vicinity of the crack become smaller, they are still tensile even when the crack has advanced to a region that was initially under compressive stress.

The stress redistribution also depends on the chosen representative volume element. Figure 7 shows a simulation with parameters identical to those in the simulation from Fig. 6, but with the crack proceeding only at one of several asperities. During crack propagation, the crack tip is more strongly unloaded because the tensile stresses in neighbouring asperities increase. These simple models show that it is not correct to infer the behaviour of cracks from a stress field calculated in a crack-free state.

To understand the stress shifts due to crack propagation, modelling crack propagation at or near the interface is important. Experimentally, it is known that cracks usually propagate only at low temperatures (Ref 32), so that the crack propagation step and the thermal cycle can be decoupled in the model.

Simulating crack propagation includes several aspects (Ref 33): (i, ii) determining whether a crack propagates; (iii) determining the propagation direction; (iv) implementing the crack opening. To determine whether (and in which direction) a crack propagates, energy release rates and/or stress intensity factors are compared to critical material parameters. Because the stress state at the crack tip is singular, special techniques can be used to calculate the stresses. Quarter-point elements (Ref 34) are designed to explicitly resolve the stress singularity at the crack tip, but they require remeshing in a crack propagation analysis. For crack propagation analyses, the XFEM method with appropriate enhancement functions (Ref 35) may be a better choice. In Ref 36, an XFEM model using a damage failure criterion is used to study crack propagation due to cooling stresses in the TBC. Alternatively, criteria using more global quantities like the frequently used $J$-integral can be used. However, this may also be problematic in a 

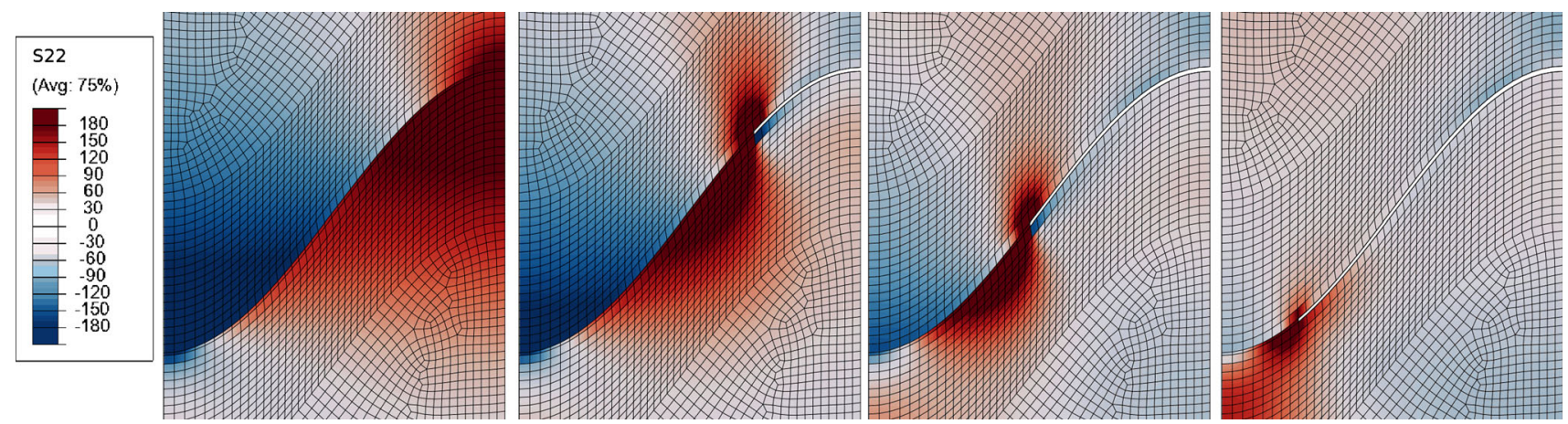

Fig. 6 Evolution of the radial stress during crack propagation at the TBC-bond coat interface. The region of tensile stress moves with the crack tip. The 2D axisymmetric model uses no TGO and is cooled

from a stress-free state with purely elastic materials. Bond coat thickness $130 \mu \mathrm{m}$, ТВC thickness $250 \mu \mathrm{m}$, substrate thickness $12.7 \mathrm{~mm}$

Fig. 7 Evolution of the radial stress during crack propagation at the TBC-bond coat interface. Tensile stresses in front of the crack tip are reduced if the crack does not propagate at every asperity due to the chosen boundary condition. The 2D axisymmetric model uses no TGO and is cooled from a stress-free state with purely elastic materials. Bond coat thickness $130 \mu \mathrm{m}$, TBC thickness $250 \mu \mathrm{m}$, substrate thickness $12.7 \mathrm{~mm}$. The colour scale is identical to that of Fig. 6
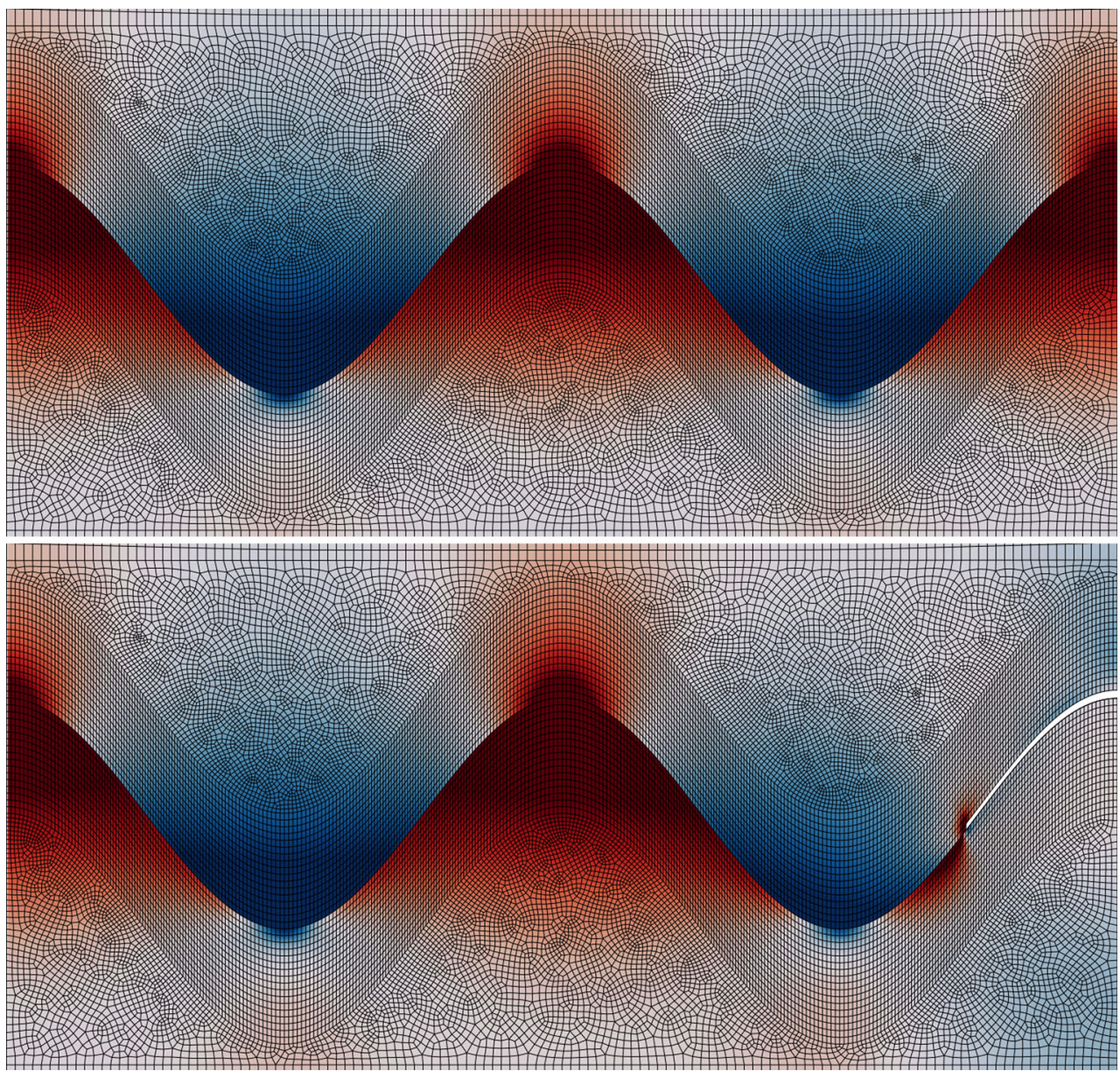

TBC system due to the presence of the interface because contours around the crack tip may cross a stiffness discontinuity that contributes to the $J$-Integral as well and needs to be accounted for. A method for doing this was presented in Ref 37. Alternatively, cohesive or damage models using a traction-separation law can be employed (Ref 38, 3). Another possibility is to advance a crack in a trial simulation and measure the energy release in the model to decide whether to accept this crack advance step or not (Ref 11).

How the crack propagation direction is determined depends on the method chosen for the finite element implementation. In many techniques (cohesive elements, node-separation), the crack propagation direction is determined beforehand. In this case, the crack propagates in the predetermined direction when the criterion for crack 
propagation has been fulfilled. This technique is appropriate in many cases in the simulation of a TBC system where crack paths are frequently known from experiment. Delamination cracks are known to form preferredly at the TGO/TBC interface in many situations so that a predefined crack path at this interface may be used. Other techniques, like XFEM, allow for arbitrary crack propagation directions. In this case, a criterion (like maximum circumferential stress) to determine the crack propagation direction from the stress field is needed. A detailed discussion of such criteria can be found in Ref 33, 39 .

If several thermal cycles are simulated, cracks may close during heating due to the difference in the CTE; in this case, it is important to choose a technique that correctly implements the contact between the crack surfaces. Friction of a closed crack may affect the energy release during further crack propagation if cracks are propagating in mode II (Ref 11).

Crack propagation is also affected by the dimension of the model. On the one hand, the stress at the crack tip is different in two and three dimensions due to the different geometry factor as explained in "Interface Geometry" section. Furthermore, a growing crack in two dimension implies complete separation of the material in the third dimension with a corresponding redistribution of the load, whereas cracks may propagate only in some directions in a 3D simulation. Crack growth in three dimension may also be facilitated by the possibility to circumvent regions of low energy release rate (for example, regions with compressive stresses), whereas such regions may stop a crack in a two-dimensional simulation.

Surface (or segmentation) cracks may also be important. Zhang et al. (Ref 40) uses XFEM to study the influence of interface geometry on surface cracks. Segmentation and delamination cracks can interact because the segmentation cracks change the stress field near the interface (Ref 15).

\section{Influence of System Parameters}

\section{Material Models}

Creating a quantitatively correct model of the stress evolution requires a large number of material parameters that are often difficult to measure (like the stress relaxation behaviour of a TGO at high temperatures). In many cases, this is simply not feasible. The consequences of any uncertainty in material parameters should therefore be estimated by performing parameter variations. Material parameters that are provided in the literature should be used with care because their values depend on the exact choice of material or spraying powder and also on the process.
In most simulations, isotropic elastic properties are assumed for the materials. However, because the TBC is applied by plasma-spraying, it contains microcracks and its elastic behaviour is different in tension and compression (Ref 41). Usually, this effect is neglected in finite element simulations; a model incorporating this is presented in Ref 23. In Ref 27, the XFEM method is used to model cracks within the splat structure of a TBC.

Stresses in the TBC may also increase due to sintering because the problem is strain-controlled so that an increase in Young's modulus causes an increase in the stresses. To model sintering, a time-dependent increase in Young's modulus can be used (Ref 4, 42). More involved techniques can also be utilized; for example, in Ref 23 a micromechanically based model that assumes that sintering is due to the healing of microcracks is used.

It is well-known that stress relaxation is important in understanding the stress evolution of TBCs as already explained in "Causes of Stress" section (Ref 6, 43). Stress relaxation at high temperature has frequently been simulated using time-independent plasticity; however, it was shown in Ref 12 that there is a pronounced difference in the stress evolution in plastic versus visco-plastic materials because visco-plastic stress relaxation counteracts plastic ratcheting. Thus, if plasticity only is implemented in a model, plastic ratcheting effects will be overestimated.

In general, determining the correct stress relaxation behaviour of the materials (especially the very thin TGO) is difficult. Because lifetime limiting cracks usually form at low temperatures, uncertainties in the material behaviour at high temperatures may be acceptable if stress relaxation is sufficiently large so that stresses at low temperature are dominated by the CTE mismatch. Nevertheless, calculated stress values should always be interpreted with care.

It is also important to provide the correct temperature dependence of material properties. If data are only available for a limited temperature range, they should be extrapolated explicitly and in a consistent way because finite element programmes usually assume that values are constant outside of the limits stated. For example, if the coefficient of thermal expansion is only known up to a temperature below the maximum temperature, it will be underestimated at maximum temperature because the CTE in almost all materials increases with temperature. This can cause a severe overestimation of thermal stresses. In using CTE values from the literature, care also has to be taken whether these values are differential or integrated with respect to a reference temperature.

More complex aspects of material properties or their behaviour (for example phase changes in the bond coat or the complex microstructure of the TGO) may also influence the stress evolution, see "Open Questions" section. 


\section{Thermal Boundary Conditions}

Thermal barrier coatings require a thermal gradient to protect the substrate from the temperature of the process gas. Therefore, simulations that are supposed to resemble the situation within a turbine have to include this thermal gradient. Experimentally realizing a thermal gradient is often difficult and thermal barrier coatings are frequently tested under isothermal conditions, either by long-term exposure or with thermal cycling.

The choice of thermal boundary conditions affects finite element simulations in several ways. First, in an isothermal simulation, the thermal conductivity of the materials is basically irrelevant as long as it is sufficiently large to ensure a homogeneous temperature throughout the simulation volume. (Alternatively, the temperature of the model can simply be prescribed as an external field.) If a thermal gradient is present, the thermal conductivity determines how the temperature is distributed (Ref 10). Transient effects during heating and cooling may also play an important role, especially if the temperature changes over a short time as in rocket engines (Ref 44).

The choice of thermal boundary conditions strongly affects the in-plane stress state inside the coating. Isothermal loading will cause tensile in-plane stresses during heating in a typical TGO/TBC because the CTE of the substrate is larger than that of the ceramic components. If stresses relax during hot time, this will cause compressive in-plane stresses upon cooling.

On the other hand, with a sufficiently large thermal gradient, the in-plane loading of the coating tends to be compressive at maximum temperature because $\alpha_{\text {substrate }} T_{\text {substrate }}<\alpha_{\text {coating }} T_{\text {coating. }}$. If stress relaxation occurs, tensile stresses may develop upon cooling that may drive segmentation cracks.

The previous consideration may seem to suggest that isothermal simulations (or experiments) are too far from realistic conditions to be useful. This is not the case. In many coating systems, coating failure is driven by normal stresses at the TBC/TGO/BC-interfaces. Because these stresses are partially due to the mismatch in the CTE of the materials, failure of the coating can be provoked by increasing the temperature at the interface. Isothermal experiments are highly suitable for this.

Finally, it should be kept in mind that using a thermal gradient requires more care in modelling the substrate behaviour (see "Influence of Substrate" section).

\section{Choice of Thermal Cycle}

In addition to thermal boundary conditions, the appropriate thermal cycle needs to be chosen.
If the system can be assumed to be stress-free at high temperature, a simple cooling analysis from this stress-free state gives information about thermal mismatch stresses. This type of cycle is relevant either for systems where strong stress relaxation in all components is expected (as, for example, in Ref 19) or to disentangle thermal mismatch stresses from other stresses. However, a simple separation of thermal mismatch stresses and stresses during hot time (as done, for example, in Ref 45,31 ) is only possible if the stress-strain relation is linear.

Usually, the stress state is determined by a complex interplay of thermal mismatch stresses, oxide growth stresses in the TGO, and stress relaxation. Stress relaxation may be plastic or visco-plastic. If no visco-plasticity and no TGO growth are present, there is no need to simulate more than two thermal cycles because each further cycle will exactly reproduce the second cycle. Running several cycles is important if materials are visco-plastic or TGO growth is modelled. Other time-dependent processes that may require the simulation of several cycles are damage in one of the materials [which may happen in rocket engines (Ref 46)] or sintering (see "Material Models" section).

Sometimes, residual stresses due to the initial coating process are simulated, for example by assuming that the system starts stress-free at some elevated temperature (Ref 5). This may be of special interest if the lifetime of the system is short. If a large number of cycles are simulated and if stress relaxation occurs, the initial residual stresses will usually not influence the final stress state at failure.

If visco-plastic behaviour is assumed, it is also important to correctly model the cooling and heating phase of the cycle because creep deformation starts at different temperatures in the different materials. Even in a simple simulation where the system is rapidly cooled from a stressfree state, stress relaxation due to creep is important, especially in the bond coat where creep at higher temperature is usually large (Ref 45). Time increments must be chosen sufficiently small in the simulation due to the strong temperature dependence of the creep strength. If time increments are too large during cooling, the rapid temperature change can cause a miscalculation of the creep strains, depending on how the programme integrates the strain over a single time increment.

\section{Influence of Substrate}

Although stresses in the coating are governing the lifetime, the substrate plays an important role because it drives the in-plane deformation. Without the substrate, the in-plane stress state of BC and TBC (and also of the TGO, if present) depends on their relative thickness, their Young's modulus, and the difference in their CTE. If a (thick) substrate is present, the stiffness of the substrate far 
exceeds that of the coating so that the in-plane thermal expansion of the structure is determined by the CTE of the substrate. Note that, as discussed in "Causes of Stress" section, the in-plane thermal expansion also changes the stress state at the interface (Ref 16) so that this effect is important even if the focus of the study is the stresses at the interface.

How the stress state develops strongly depends on the thermal boundary conditions. In an isothermal experiment (or simulation), the stress in the substrate is practically homogeneous everywhere. If the substrate is sufficiently thick, stresses are small so that only the elastic properties of the substrate are relevant.

If a thermal gradient is present, significant stresses can also develop in the substrate. Plastic and visco-plastic deformations near the coating interface become important and influence the stress state. In this case, it is important to correctly describe the material behaviour of the substrate.

\section{Implementation of Oxide Growth}

The growth of the TGO changes the stress distribution in a TBC system in two different ways: on the one hand, the volume increase associated with the growth (Pilling-Bedworth-ratio, see Ref 10) causes compressive stresses, on the other hand, the low coefficient of thermal expansion of the TGO changes the thermal mismatch patterns. Both effects tend to put the peak region of the asperities under compressive and the valley region under tensile stresses. The TGO grows in thickness mainly on the bond coat side of the TGO. In addition, there is some lateral growth within the TGO, but this is usually considerably smaller (Ref 7).

There are different ways to implement the growth of the TGO. The volume increase in the TGO during growth can be modelled as a form of material swelling [this swelling can also be emulated by using an artificial thermal expansion (Ref 6)], i.e., the volume of the elements increases (Ref 31). In addition, the growth in thickness direction can also be implemented by changing the material properties of elements in the bond coat to those of the TGO (Ref 6). Swelling is then added both to these elements and to those that have already been changed to simulate lateral growth. It is also possible to distinguish internal and external oxidation at the interface (Ref 47$)$.

How swelling is implemented may influence the stress state, especially if the TGO is assumed to have a high creep strength so that stresses cannot be relaxed at high temperatures. Consider a TGO that consists of several elements in the thickness direction. The simplest method to model the TGO growth is to simply assume isotropic swelling of each element in the TGO. In this case, the lateral growth stresses are overestimated so that compressive stresses within the TGO and at the peak of the TBC are very large.
If anisotropic swelling is used with the same material parameters everywhere inside the TGO, the lateral growth stresses are reduced, but the stress distribution is still rather homogeneous in the TGO. Since most of the TGO growth actually occurs directly at the bond coat side, it may be even more realistic to apply a different growth law to the lowest row of elements directly adjacent to the bond coat than to the other elements so that elements not adjacent to the bond coat only grow in lateral direction. In this latter case, those elements in the TBC not adjacent to the bond coat can shield the TBC from some of the growth stresses so that the stress distribution is different from that in the other simulation techniques. In Ref 48, different simulation techniques for TGO growth are compared, showing that stress discontinuities may form if thickness growth is restricted to the lowest row of elements, whereas a more sophisticated implementation method may avoid this problem.

Due to the parabolic growth law, the TGO growth rate depends on the thickness of the TGO. In implementing TGO growth, the growth rate therefore has to be adapted to the current thickness of the TGO. To do so, the thickness of the TGO has to be measured during the simulation. It is important not to simply rely upon a growth rate law that is calculated beforehand, for the thickness of the TGO may deviate considerably due to creep because large lateral stresses may cause a material flow that increases the TGO thickness more rapidly than expected.

Frequently, the growth rate is considered as constant during a holding cycle, so that the thickness can be evaluated once per cycle. Although this simplification slightly overestimates the TGO growth and therefore the occurring growth stresses, this effect is small for short holding times and thick TGOs. If the TGO growth per cycle is significant, it is necessary to adapt the growth rate and also to ensure that the correct ratio of lateral to perpendicular growth is maintained throughout the simulation.

It should also be kept in mind that the microstructure of the TGO is also strongly inhomogeneous-how this affects the material properties and the stress evolution has so far not been studied, see "Microstructure" section.

\section{Open Questions}

\section{Crack Propagation During Thermal Cycling}

Experimentally, it is known that microdelaminations form in an early stage of the TBC lifetime (Ref 32). These microdelaminations tend to grow slowly and only become critical after the TGO has grown sufficiently.

So far, finite element simulations of delaminations frequently do not reproduce this behaviour accurately. Due to 
the redistribution of stresses (see Fig. 6 and 7), the stress intensity factor at the crack tip usually increases during crack growth so that cracks do not stop, although there are simulations where crack stopping was observed (Ref 49), but only for a small range of material parameters. As Fig. 7 shows, the crack tip is unloaded more strongly when modelling small cracks in larger volume.

There are several possible explanations for this: the complex three-dimensional interface shape may strongly affect crack propagation, especially when the cracks cover only a small part of the interface, similar to the stress redistribution shown in Fig. 7. Many material models do not take sintering into account which serves to increase the energy release rate of a propagating crack due to the increase in the stiffness (see "Material Models" section). Finally, R-curve behaviour (see "Material Behaviour" section) in the TBC may play an important role here.

\section{Microstructure}

APS-sprayed thermal barrier coatings have a complex microstructure consisting of splats with cracks between and within the splats. This splat structure causes anisotropic material behaviour. Young's modulus is different in compression and tension, especially in the vertical direction perpendicular to the splats (Ref 41). So far, these effects are not routinely implemented [although there are exceptions (Ref 23)]. Furthermore, crack growth may also be affected with cracks propagating preferredly between splats. How this anisotropy influences the failure behaviour is largely unknown so far.

The microstructure of the TGO is also more complex than accounted for in most simulations: the TGO grows inward towards the bond coat side. Initially, small grains that also contain spinels are formed, but with further growth of the TGO, grains growing inwards become larger, resulting in a columnar grain structure (Ref 50). This can be expected to have some influence on the mechanical properties due to grain-boundary diffusion being more pronounced in the lower than in the upper part of the TGO and also due to microcrack formation and healing if the material is thermally cycled.

\section{Material Behaviour}

Material properties of thin coatings are difficult to determine, especially those of the TGO. It is clear that some mechanism to relax stresses has to be present in the TGO because stresses due to lateral growth would reach values of several ten Gigapascal if the TGO is assumed to be purely elastic at all temperatures, whereas measured stresses are about $4 \mathrm{GPa}$ (Ref 18). However, the detailed mechanism is not clear; relaxation may be due to creep (Ref 51), but microcracking and subsequent healing may also play a role (Ref 52 ). As explained in the previous section, the TGO behaviour is probably not homogeneous due to the changing microstructure. Measuring the material properties of a TGO would therefore strongly improve finite element simulations because these properties are often the greatest source of uncertainty in setting up the model.

Crack propagation simulations also need information about the crack resistance. Techniques to measure the critical energy release rate at the coating interfaces are described in Ref 53, 54, 55. However, it is very difficult to perform measurements of the interface properties after a TGO has grown.

The crack resistance of the materials themselves is also of interest. Cracks are frequently observed to grow inside the TBC or the TGO (Ref 1). For the behaviour of microcracks in the TBC, R-curve behaviour, which is known to occur in yttria-stabilized zirconia (Ref 56) may be important because it may contribute to the stopping of microcracks as explained above.

It has also been shown that moisture may affect the cracking of TBCs at room temperature in the so-called "desktop effect" (Ref 57). This effect and how it affects the lifetime of TBCs is not very well understood so far.

The material behaviour of the bond coat may also change over time due to the depletion in aluminium that forms the TGO, triggering spallation of the TBC (Ref 58). Experimentally, it was shown in Ref 14 that cracks may form in this depleted zone when a specimen is tested with a thermal gradient and superimposed mechanical load. Therefore, further investigation of the material behaviour of MCrAlY bond coats may also be of interest to make simulations more realistic.

\section{Validation and Verification}

To validate a finite element model, comparisons to analytical calculations can be performed, see, for example (Ref 59), providing evidence concerning the technical soundness of a simulation.

Verifying a FE simulation of a TBC system by comparing it directly to coatings applied in a gas turbine is very difficult because conditions in a turbine are highly complex. Instead, comparisons with model experiments are usually performed, using isothermal or cyclic thermal exposure in oven experiments (Ref 60), mechanical testing at high temperatures with or without a thermal gradient (Ref 61), or burner rig (Ref 62) or laser testing (Ref 63). Furthermore, model TBC systems with controlled interface roughness or a simplified coating structure can be used (Ref 64). 
Even so, verification using experimental results is difficult due to the complex microstructure and interface and to the uncertainties in the material behaviour. Stresses perpendicular to the interface cannot be measured experimentally, so that a direct comparison between simulation and experiment is not possible. (In-plane stresses can be measured (Ref 18); but these are dominated by the TGO growth as explained above.) A direct experimental verification of the calculated stresses is therefore rather difficult.

If crack propagation is simulated, it is possible to compare the simulation results to experimentally produced cracks. Depending on the simulation parameters, especially the material behaviour, cracks may be expected to form either at peaks or valleys of the roughness profile. A comparison with micrographs can serve as a verification of this prediction (Ref 15). The discrepancy due to the experimentally observed slow crack growth in an incubation phase was already discussed in "Crack Propagation During Thermal Cycling" section. Reproducing this incubation time faithfully would serve as verification of the finite element model.

Finite element models can serve as a basis for lifetime models [see, for example, (Ref 61, 42)], and an agreement between the lifetime model and experiments may be considered as an experimental verification of the model (Ref $65,60)$. However, there usually is a larger number of unknown model parameters that have to be adapted so that the verification of the model is rather indirect.

In general, the large number of unknowns in a TBC system implies that there is a large number of free parameters in any finite element model. Experimentally verifying the model in the strict sense would require to determine all unknown parameters from one set of experiments (for example, by adapting the parameters until there is agreement between the model and the experiments) and then making predictions for a different experiment with different conditions.

\section{Conclusions}

In this paper, an overview of important issues in modelling the stress and failure evolution of thermal barrier coatings was presented. The goal of finite element simulations is to yield insights into the system under study that allow meaningful comparisons to experiments to be drawn. This requires a thorough understanding of different causes of stresses (CTE mismatch, TGO growth, influence of stress relaxation, influence of compression due to the substrate, etc.) to decide which effects are to be modelled.

There is a large number of modelling choices to be made (dimensionality, boundary conditions, material behaviour, inclusion of crack propagation, etc.) that influence the final result. Due to the large number of uncertainties, especially in material behaviour of thin films at elevated temperatures, it may in many cases be futile to actually create a model that can make detailed quantitative predictions. Finite element models are nevertheless a valuable tool because they allow to understand how the stress evolution is affected by different effects.

Although finite element simulations of thermal barrier coatings have been performed for a long time and have yielded a large number of valuable insights, there are still open questions to address regarding modelling cracks and the complex microstructure. In addition, more experimental input regarding material properties of individual layers and behaviour of full coating systems are required in order to fully understand all aspects of stress evolution and failure.

\section{References}

1. N.P. Padture, M. Gell, and E.H. Jordan, Thermal Barrier Coatings for Gas-Turbine Engine Applications, Science, 2002, 296(5566), p 280-284

2. H. Evans, Oxidation Failure of TBC Systems: An Assessment of Mechanisms, Surf. Coat. Technol., 2011, 206(7), p 1512-1521

3. M. Białas, Finite Element Analysis of Stress Distribution in Thermal Barrier Coatings, Surf. Coat. Technol., 2008, 202(24), p 6002-6010. doi:10.1016/j.surfcoat.2008.06.178.

4. E.P. Busso, Z.Q. Qian, M.P. Taylor, and H.E. Evans, The Influence of Bondcoat and Topcoat Mechanical Properties on Stress Development in Thermal Barrier Coating Systems, Acta Mater., 2009, 57(8), p 2349-2361. doi:10.1016/j.actamat.2009.01.017.

5. G.C. Chang, W. Phucharoen, and R.A. Miller, Finite Element Thermal Stress Solutions for Thermal Barrier Coatings, Surf. Coat. Technol.,1987, 32(1-4), p 307-325. doi:10.1016/02578972(87)90116-2.

6. A.M. Freborg, B.L. Ferguson, G.J. Petrus, and W.J. Brindley, Modeling Oxidation Induced Stresses in Thermal Barrier Coatings, Mater. Sci. Eng., 1998 A245, p 182-190

7. A.M. Karlsson and A. Evans, A Numerical Model for the Cyclic Instability of Thermally Grown Oxides in Thermal Barrier Systems, Acta Mater., 2001, 49(10), p 1793-1804

8. L. Wang, Y. Wang, X. Sun, J. He, Z. Pan, and C. Wang, Finite Element Simulation of Residual Stress of Double-Ceramic-Layer La 2 Zr 2 o 7/8YSZ Thermal Barrier Coatings Using Birth and Death Element Technique, Comput. Mater. Sci., 2012, 53(1), p 117-127

9. K. Khor and Y. Gu, Effects of Residual Stress on the Performance of Plasma Sprayed Functionally Graded $\mathrm{zro}_{2} /$ Nicocraly Coatings, Mater. Sci. Eng. A, 2000, 277(1), p 64-76

10. R. Bürgel, H.J. Maier, and T. Niendorf, Handbuch Hochtemperatur-Werkstofftechnik, 4th edn. (Vieweg+Teubner, Braunschweig/ Wiesbaden, 2011).

11. M. Bäker and J. Rösler, Simulation of Crack Propagation in Thermal Barrier Coatings with Friction, Comput. Mater. Sci., 2012, 52(1), p 236-239.

12. M. Bäker, Influence of Material Models on the Stress State in Thermal Barrier Coating Simulations, Surf. Coat. Technol., 2014, 240, p 301-310

13. H. Guo, R. Vaßen, and D. Stöver, Atmospheric Plasma Sprayed Thick Thermal Barrier Coatings with High Segmentation Crack Density, Surf. Coat. Technol., 186(3), p 353-363 
14. M. Bartsch, B. Baufeld, S. Dalkiliç, L. Chernova, and M. Heinzelmann, Fatigue Cracks in a Thermal Barrier Coating System on a Superalloy in Multiaxial Thermomechanical Testing, Int. J. Fatigue, 2008, 30(2), p 211-218

15. P. Seiler, M. Bäker, and J. Rösler, Multi-scale Failure Mechanisms of Thermal Barrier Coating Systems, Comput. Mater. Sci., 2013, 80, p 27-34

16. M. Bäker, J. Rösler, and E. Affeldt, The Influence of Axial Loading on the Interface Stresses of Thermal Barrier Coatings, Comput. Mater. Sci. , 2009, 47(2), p 466-470. doi:10.1016/j. commatsci.2009.09.012.

17. P. Seiler, M. Bäker, and J. Rösler, Influence of Creep and Cyclic Oxidation in Thermal Barrier Coatings, Int. J. Mater. Res., 2012, 103(1), p 50-56

18. D. Clarke, R. Christensen, and V. Tolpygo, The Evolution of Oxidation Stresses in Zirconia Thermal Barrier Coated Superalloy Leading to Spalling Failure, Surf. Coat. Technol., 1997, 94, p 89-93

19. M. Gupta, K. Skogsberg, P. Nyle, S. Korea, M. Gupta, K. Skogsberg, and P. Nyle, Influence of Topcoat-Bondcoat Interface Roughness on Stresses and Lifetime in Thermal Barrier Coatings, J. Therm. Spray Technol., 2014, 23, p 170-181. doi:10.1007/ s11666-013-0022-9.

20. M. Jinnestrand and H. Brodin, Crack Initiation and Propagation in Air Plasma Sprayed Thermal Barrier Coatings, Testing and Mathematical Modelling of Low Cycle Fatigue Behaviour, Mater. Sci. Eng. A, 2004, 379(1-2), p 45-57. doi:10.1016/j.msea. 2003.12.063.

21. M. Jinnestrand and S. Sjöström, Investigation by 3D FE Simulations of Delamination Crack Initiation in TBC Caused by Alumina Growth. Surf. Coat. Technol., 2001, 135(2-3), p 188195. doi:10.1016/S0257-8972(00)01084-7.

22. M. Schweda, T. Beck, and L. Singheiser, Influence of Bondcoat Creep and Roughness on Damage and Lifetime of $\mathrm{ZrO}_{2}$ TBCs for Gas Turbines Under Thermocyclic Loads, J. Phys. Conf. Ser., 2010, 240(1), p 012077

23. S. Asghari and M. Salimi, Finite Element Simulation of Thermal Barrier Coating Performance Under Thermal Cycling, Surf. Coat. Technol., 2010, 205(7), p 2042-2050. doi:10.1016/j.surfcoat. 2010.08.099.

24. P. Bednarz, Finite Element Simulation Stress Evolution in Thermal Barrier Coating Systems, Ph.D. thesis, Forschungszentrum Jülich (2007)

25. C.H. Hsueh, J.A. Haynes, M.J. Lance, P.F. Becher, M.K. Ferber, E.R. Fuller, S.A. Langer, W.C. Carter, and W.R. Cannon, Effects of Interface Roughness on Residual Stresses in Thermal Barrier Coatings, J. Am. Ceram. Soc., 1999, 82, p 1073-1075

26. A.D. Jadhav, N.P. Padture, E.H. Jordan, M. Gell, and P. Miranzo, Low-Thermal-Conductivity Plasma-Sprayed Thermal Barrier Coatings with Engineered Microstructures, Acta Mater., 2006, 54, p 3343-3349. doi:10.1016/j.actamat.2006.03.024.

27. P. Michlik and C. Berndt, Image-Based Extended Finite Element Modeling of Thermal Barrier Coatings, Surf. Coat. Technol., 2006, 201(6), p 2369-2380. doi:10.1016/j.surfcoat.2006.04.003.

28. N. Nayebpashaee, S. Seyedein, M. Aboutalebi, H. Sarpoolaky, and S. Hadavi, Finite Element Simulation of Residual Stress and Failure Mechanism in Plasma Sprayed Thermal Barrier Coatings Using Actual Microstructure as the Representative Volume, Surf. Coat. Technol., 2016, 291, p 103-114

29. J. Rosler, H. Harders, and M. Baker, Mechanical Behaviour of Engineering Materials (Springer, New York 2007)

30. R. Ghafouri-Azar, J. Mostaghimi, and S. Chandra, Modeling Development of Residual Stresses in Thermal Spray Coatings. Comput. Mater. Sci., 2006, 35(1), p 13-26. doi:10.1016/j.com matsci.2005.02.007.
31. J. Rösler, M. Bäker, and K. Aufzug, A Parametric Study of the Stress State of Thermal Barrier Coatings. Part I: Creep Relaxation, Acta Mater., 2004, 52(16), p 4809-4817. doi:10.1016/j. actamat.2004.06.046.

32. O. Trunova, P. Bednarza, R. Herzog, T. Beck, and L. Singheiser, Microstructural and Acoustic Damage Analysis and Finite Element Stress Simulation of Air Plasma-Sprayed Thermal Barrier Coatings Under Thermal Cycling, Int. J. Mater. Res. (formerly Zeitschrift für Metallkunde), 2008, 99(10), p 1129-1135. doi:10. 3139/146.101741.

33. M. Bäker, S. Reese, and V. Silberschmidt, Simulation of Crack Propagation Under Mixed-Mode Loading, in Handbook of Mechanics of Materials, ed. C. Hsueh, S. Schmauder, C. Chen, K. Chawla, N. Chawla, W. Chen, and K.Y. (Springer, Germany, In press)

34. I.L. Lim, I.W. Johnston, and S.K. Choi, Comparison Between Various Displacement-Based Stress Intensity Factor Computation Techniques, Int. J. Fract., 1992, 58(3), p 193-210. doi:10.1007/ BF00015615.

35. M. Duflot, A Study of the Representation of Cracks with Level Sets. Int. J. Numer. Meth. Eng., 2007, 70(11), p 1261-1302. doi:10.1002/nme.1915.

36. S. Kyaw, I. Jones, and T. Hyde, Simulation of Failure of Air Plasma Sprayed Thermal Barrier Coating Due to Interfacial and Bulk Cracks Using Surface-Based Cohesive Interaction and Extended Finite Element Method, J. Strain Anal. Eng. Des., 2016, 51(2), p 132-143

37. F. Guo, L. Guo, K. Huang, X. Bai, S. Zhong, and H. Yu, An Interaction Energy Integral Method for t-Stress Evaluation in Nonhomogeneous Materials Under Thermal Loading, Mech. Mater., 2015, 83, p 30-39

38. K. Al-Athel, K. Loeffel, H. Liu, and L. Anand, Modeling Decohesion of a Top-Coat from a Thermally-Growing Oxide in a Thermal Barrier Coating, Surf. Coat. Technol., 2013, 222, p 6878. doi:10.1016/j.surfcoat.2013.02.005.

39. P. Bouchard, F. Bay, and Y. Chastel, Numerical Modelling of Crack Propagation: Automatic Remeshing and Comparison of Different Criteria, Comput. Methods Appl. Mech. Eng., 2003, 192(35-36), p 3887-3908. doi:10.1016/S0045-7825(03)00391-8.

40. W. Zhang, X. Fan, and T. Wang, The Surface Cracking Behavior in Air Plasma Sprayed Thermal Barrier Coating System Incorporating Interface Roughness Effect, Appl. Surf. Sci., 258(2), p 811-817

41. T. Wakui, J. Malzbender, and R. Steinbrech, Strain Dependent Stiffness of Plasma Sprayed Thermal Barrier Coatings, Surf. Coat. Technol., 2006, 200(16), p 4995-5002

42. R. Vaßen, S. Giesen, and D. Stöver, Lifetime of Plasma-Sprayed Thermal Barrier Coatings: Comparison of Numerical and Experimental Results, J. Therm. Spray Technol., 2009, 18(5-6), p $835-845$

43. J. Rösler, M. Bäker, and M. Volgmann, Stress State and Failure Mechanisms of Thermal Barrier Coatings: Role of Creep in Thermally Grown Oxide, Acta Mater., 2001, 49(18), p 3659-3670

44. M. Bäker, T. Fiedler, and J. Rösler, Stress Evolution in Thermal Barrier Coatings for Rocket Engine Applications, Mech. Adv. Mater. Modern Process., 2015, 1(1), p 1-10

45. M. Bäker, J. Rösler, and G. Heinze, A Parametric Study of the Stress State of Thermal Barrier Coatings Part II: Cooling Stresses, Acta Mater., 2005, 53(2), p 469-476. doi:10.1016/j.actamat. 2004.10.004.

46. M. Fassin, S. Wulfinghoff, and S. Reese, Modelling Thermal Barrier Coatings and Their Influence on the Lifetime of Rocket Engine Nozzle Structures, In: VII European Congress on Computational Methods in Applied Sciences and Engineering. ECCOMAS, 2016 
47. E. Busso, J. Lin, S. Sakurai, and M. Nakayama, A mechanistic Study of Oxidation-Induced Degradation in a Plasma-Sprayed Thermal Barrier Coating System. Part I: Model Formulation, Acta Mater., 2001, 49(9), p 1515-1528

48. X. Huang, J. Wang, K. Song, F. Zhang, T. Yi, and J. Ding, A Comparative Study for Modeling Displacement Instabilities Due to TGO Formation in TBCs of High-Temperature Components in Nuclear Power Plant, Sci. Tech. Nucl. Install., 2016. doi:10.1155/ 2016/2857065

49. M. Bäker, Finite Element Simulation of Interface Cracks in Thermal Barrier Coatings. Comput. Mater. Sci, 2012, 64, p 79-83 (2012). doi:10.1016/j.commatsci.2012.02.044. Proceedings of the 21st International Workshop on Computational Mechanics of Materials (IWCMM 21)

50. M. Karadge, X. Zhao, M. Preuss, and P. Xiao, Microtexture of the Thermally Grown Alumina in Commercial Thermal Barrier Coatings, Scr. Mater., 2006, 54(4), p 639-644

51. J. Cho, C. Wang, H. Chan, J. Rickman, and M. Harmer, Role of Segregating Dopants on the Improved Creep Resistance of Aluminium Oxide. Acta materialia 47(15), 4197-4207 (1999).

52. M. Schütze, Protective Oxide Scales and Their Breakdown (Wiley, Chichester 1997).

53. G.W. Dransmann, R.W. Steinbrech, A. Pajares, F. Guiberteau, A. Dominguez-Rodriguez, and A.H. Heuer, Indentation Studies on $\mathrm{Y}_{2} \mathrm{O}_{3}$ “ $=$ Stabilized $\mathrm{ZrO}_{2}$ : II, Toughness Determination from Stable Growth of Indentation" = Induced Cracks, J. Am. Ceram. Soc., 1994, 77(5), p 1194-1201. doi:10.1111/j.1151-2916.1994. tb05392.x

54. Y. Yamazaki, A. Schmidt, and A. Scholz, The Determination of the Delamination Resistance In Thermal Barrier Coating System by Four-Point Bending Tests, Surf. Coat. Technol., 2006, 201(3), p 744-754

55. W. Zhu, L. Yang, J. Guo, Y. Zhou, and C. Lu, Determination of Interfacial Adhesion Energies of Thermal Barrier Coatings by Compression Test Combined with a Cohesive Zone Finite Element Model, Int. J. Plast., 2015, 64, p 76-87. doi:10.1016/j.ijplas. 2014.08.003. http://www.sciencedirect.com/science/article/pii/ S074964191400151X.

56. M.S. Kaliszewski, G. Behrens, A.H. Heuer, M.C. Shaw, D.B. Marshall, G.W. Dransmanri, R.W. Steinbrech, A. Pajares, F.
Guiberteau, F.L. Cumbrera et al., Indentation Studies on $\mathrm{y}_{2} \mathrm{O}_{2}-$ Stabilized $\mathrm{zro}_{2}$ : I, Development of Indentation-Induced Cracks, $J$. Am. Ceram. Soc., 1994, 77(5), p 1185-1193

57. M. Rudolphi, D. Renusch, H.E. Zschau, and M. Schütze, The Effect of Moisture on the Delayed Spallation of Thermal Barrier Coatings: Vps Nicocraly Bond Coat+ APS YSZ Top Coat, Mater. High Temp., 2009, 26(3), p 325-329

58. E. Shillington and D. Clarke, Spalling Failure of a Thermal Barrier Coating Associated with Aluminum Depletion in the Bond-Coat, Acta Mater., 1999, 47(4), p 1297-1305

59. M. Ahrens, R. Vaßen, and D. Stöver, Stress Distributions in Plasma-Sprayed Thermal Barrier Coatings as a Function of Interface Roughness and Oxide Scale Thickness, Surf. Coat. Technol., 2002, 161(1), p 26-35. doi:10.1016/S0257-8972(02)00 359-6

60. O. Trunova, T. Beck, R. Herzog, R. Steinbrech, and L. Singheiser, Damage Mechanisms and Lifetime Behavior of Plasma Sprayed Thermal Barrier Coating Systems for Gas Turbines Part I: Experiments, Surf. Coat. Technol., 2008, 202(20), p 5027-5032

61. H. Aleksanoglu, A. Scholz, M. Oechsner, C. Berger, M. Rudolphi, M. Schütze, and W. Stamm, Determining a Critical Strain for APS Thermal Barrier Coatings Under Service Relevant Loading Conditions, Int. J. Fatigue, 2013, 53, p 40-48.

62. R. Vaßen, F. Cernuschi, G. Rizzi, A. Scrivani, N. Markocsan, L. Östergren, A. Kloosterman, R. Mevrel, J. Feist, and J. Nicholls, Recent Activities in the Field of Thermal Barrier Coatings Including Burner Rig Testing in the European Union, Adv. Eng. Mater., 2008, 10(10), p 907-921

63. J. Schloesser, M. Bäker, and J. Rösler, Laser Cycling and Thermal Cycling Exposure of Thermal Barrier Coatings on Copper Substrates, Surf. Coat. Technol., 2011, 206(7), p 1605-1608

64. T. Beck, M. Schweda, and L. Singheiser, Influence of Interface Roughness, Substrate and Oxide-Creep on Damage Evolution and Lifetime of Plasma Sprayed Zirconia-Based Thermal Barrier Coatings, Proc. Eng., 2013, 55, p 191-198

65. T. Beck, R. Herzog, O. Trunova, M. Offermann, R.W. Steinbrech, and L. Singheiser, Damage Mechanisms and Lifetime Behavior of Plasma-Sprayed Thermal Barrier Coating Systems for Gas Turbines Part II: Modeling, Surf. Coat. Technol., 2008, 202(24), p 5901-5908 